\title{
Reliability and Validity of Measurement Using Smart Phone- Based Goniometer on Pelvic Tilting Angle in Standing and Sitting Position
}

\author{
Sung-Min Ha', In-Cheol Jeon ${ }^{2}$ \\ 'Department of Physical Therapy, College of Health Science, Sangji University, Wonju; ${ }^{2}$ Department of Physical Therapy, College of Life \& Health \\ Science, Hoseo University, Asan, Korea
}

Purpose: The purpose of this study was to assess the intra-rater and inter-rater reliability and validity of pelvic tilting angle measurements using a smart phone-based inclinometer (Clino) compared to a palpation meter (PALM) in the standing and sitting position. This study used an interchangeable method with Clino to measure the pelvic tilting angle in the standing and sitting positions.

Methods: Twenty healthy subjects were recruited. Measurements of the pelvic tilting angle in the standing and sitting positions were obtained by two examiners using the Clino and PALM. A resting session was conducted 10 minutes later to assess the intra and inter rater reliability. To assess validity of the measurement using Clino, a PALM was used as the gold standard. The intra-class correlation coefficient (ICC) was used to determine the intra and inter rater reliability of Clino and a PALM. To assess the validity, the Pearson correlation coefficients were used for two measurement techniques to measure the pelvic tilting angle in the standing and sitting positions. The statistical significance was set to $\alpha=0.05$.

Results: Measurements of the pelvic tilt had high inter-rater reliability in the standing $(I C C=0.82)$ and sitting $(I C C=0.88)$ positions using Clino and intra-rater reliability in the standing $(I C C=0.87)$ and sitting $(I C C=0.91)$ positions using Clino. Measurements of the pelvic tilt had high validity by a comparison of PALM and Clino in the standing $(r=0.83)$ and sitting $(r=0.89)$ positions $(p<0.05)$.

Conclusion: The use of Clino can be recommended as a tool to replace the PALM and measure the pelvic tilt angle in the standing and sitting positions while maintaining the clinical reliability and validity.

Keywords: Clinometer, Palpation meter, Pelvic tilting angle, Reliability, Validity

\section{서 론}

골반은 안정 시에 몸통의 직립 위치를 유지할 수 있도록 지지하는 역 할을 하고, 불안정 시에는 흐트러진 신체의 균형을 회복하는 데 중요 한 역할을 한다. 골반은 위치적으로 척추와 다리를 연결하며, 골반을 통해 체중이 하체로 전달됨에 따라 기능적인 몸통 운동의 범위를 증 가시키는 데 필수적이다. 또한 골반은 골반 기저근육조직 및 골반 자 체에 의해 유지되는 복부 기관을 지지하는 중요한 기능을 수행한다. 결과적으로, 골반은 척추뼈의 정렬과 다리의 임상적 평가를 정확하 게 수행하기 위한 중요한 부위라고 볼 수 있다. 이와 같이, 골반의 정 확한 평가와 운동은 임상적으로 상당한 관심의 대상이 되어 왔으며, 그 중요성이 지속적으로 커지고 있다. 하지만 골반의 앞기울임, 뒷기
울임의 정렬이 역학적으로 변화된 자세에서는 자세 안정성, 균형, 보 행에 부정적인 영향을 미치며, 이러한 변화된 골반의 위치는 허리통 증의 위험 인자로 간주하는 허리뼈 정렬에 직접적으로 영향을 줄 수 있다. ${ }^{3,4}$

과도한 골반기울임 각도는 척추 앞굽음이 비정상적으로 증가된 상태를 의미하며, 각도가 경미할 경우 척추 앞굽음이 감소된 상태를 말한다. 따라서 이 같은 구조를 파악하기 위해 골반기울임 각도의 정 확한 평가는 치료에 앞서 임상적으로 상당히 중요하다고 할 수 있다. 골반이 앞으로 기울어진 상태인 골반 앞기울임은 넙다리네갈래근과 엉덩허리근, 넙다리근막긴장근, 엉덩관절 주머니, 엉덩관절의 앞쪽 인 대와 근막 구조의 단축과 이로 인해 생겨난 제한된 엉덩 관절 폄에 의 해 발생한다. 증가된 골반 앞기울임과 척주앞굽음증은 달리기 중 근 
골격 손상의 위험이 증가한다는 보고가 있으며, ${ }^{5}$ 배근육이나 큰볼기 근을 잘 사용하지 못하게 되어 발달을 어렵게 만들며 각종 통증을 불러올수 있다.

이와 반대로 골반이 뒤로 기울어진 상태인 골반 뒷기울임은 척추 앞굽음을 감소시켜 척추면의 반복적인 충돌이나 넙다리뒤근의 과도 한 긴장을 발생시킬 수 있으며, 삠으로 이어질 수 있다고 보고되고 있 다. ${ }^{6,7}$ 이러한 긴장된 넙다리뒤근의 길이를 신장시키기 위해 여러 스트 레칭을 실시한 결과, 스트레칭의 방법 보다는 골반을 앞기울임의 위 치로 유지하여 스트레칭을 진행하는 것이 근 신장에 유의한 효과를 나타낸다고 보고되었다. ${ }^{8}$ 이와 같은 기준에 따라 일반인과 정기적인 달리기 활동을 하는 환자의 골반 앞기울임 각도를 측정할 수 있다. ${ }^{9}$

골반 측정은 보통 서 있는 자세에서 수행되며, 경사계와 palpation meter (PALM)를 포함하여 여러가지 방법을 통해 위앞엉덩뼈가시(anterior superior iliac spine, ASIS)와 위뒤엉덩뼈가시(posterior superior iliac spine, PSIS)를 촉진하고 골반의 위치를 측정한다. ${ }^{10,11}$ 그 중 PALM은 골반의 위치를 측정하기 위해 가장 타당하고 신뢰할 수 있는 도구이 다. ${ }^{10-12}$ 수많은 선행연구들을 통해서, 신체의 정렬을 PALM을 이용한 측정에서 높은 신뢰도를 확인할 수 있었다. ${ }^{13-15}$ PALM 을 이용하면 다 리길이 차이를 측정하기 위해서 임상적으로 사용할 수 있을 뿐만 아 니라, ${ }^{33}$ 골반의 비대칭성을 검사했을 때 0.84 (이마면)과 0.98 (시상면) 의 검사자 내 신뢰도 그리고 0.65 (이마면)과 0.89 (시상면)의 검사자 간 신뢰도를 확인할 수 있었다. ${ }^{14}$ 또한 서있는 자세에서 허리골반부위 의 정렬을 측정함에 있어서 방사선촬영을 대체하여 척추의 정렬이 상을 검사하기 위해 사용되었다. ${ }^{15}$

여러 연구에서 골반 비대칭의 신뢰성 및 정량화 문제를 해결하기 위해 다양한 도구를 조사하였지만, 스마트폰 기반의 경사계 어플리 케이션인 Clino를 PALM과 비교하여 앉은 자세와 선 자세에서의 골 반 기울임 각도를 측정한 연구는 없었다. 따라서 본 연구가설은 골반 의 위치를 평가하기 위해 서 있거나 앉은 자세에서의 골반 기울임 각 도를 Clino와 PALM으로 측정하여 PALM을 대신하여 스마트폰 애플
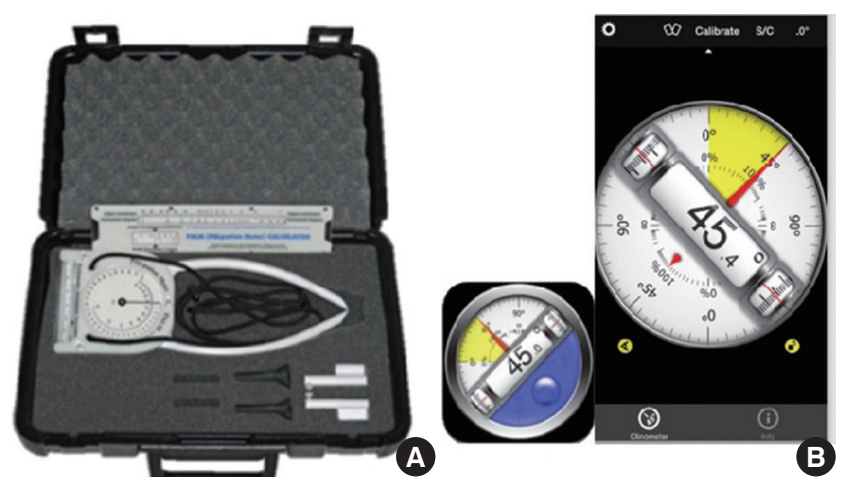

Figure 1. (A) Palpation meter (PALM), (B) Clinometer (Clino).
리케이션인 Clino를 사용 할 수 있을 것이다. 또한, 대체방법의 신뢰도 와 타당도가 기존방법에 비하여 통계학적으로 유의한 차이가 없을 것이라는 가설을 증명하려 한다.

\section{연구 방법}

\section{1. 연구대상}

건강한 20 대 여성참가자 20 명이 본 연구를 위하여 자발적으로 참여 하였다. 본 연구의 실험 프로토콜은 호서대학교 연구윤리위원회의 심의를 거처 승인되었으며, 참여한 대상자들은 실험 전 모두 자발적 참여 동의서에 서명하였다. 연구대상자의 선정기준은 척추의 올바른 정렬을 가진 자 즉, 봉우리, 엉덩뼈 능선의 가장 윗부분, 엉덩관절의 큰돌기, 종아리뼈머리 그리고 가쪽 복사뼈가 수직선 위에 위치한 자 이다. ${ }^{16}$ 허리 원반탈출증 수술을 받은 지 6 개월 이내의 대상자는 제외 하였다. 실험에 참가한 대상자들의 특성은 다음과 같다(Table 1).

\section{2. 측정 장비 및 기기}

바로 선 자세와 앉은 자세에서 위앞엉덩뼈가시와 위뒤엉덩뼈가시를 찾아 PALM을 사용하여 골반의 기울기를 측정하였다. 동일한 스마트 폰 기종에 설치한 어플리케이션 Clino (모델명: Clinometer+bubble lev$\mathrm{el}$, 개발자: plaincord) 또한 PALM (PAA 12-1180, PALpation Meter, baseline, USA)과 같은 방법으로 바로 선 자세와 앉은 자세에서 위앞엉덩 뼈가시와 위뒤엉덩뼈가시를 찾아 그 사이를 테이프로 붙이고 골반

Table 1. General characteristics of the subjects

$(\mathrm{N}=20)$

\begin{tabular}{lr}
\hline & Mean \pm SD \\
\hline Age $(\mathrm{yr})$ & $21 \pm 1.6$ \\
Height $(\mathrm{cm})$ & $163.7 \pm 4.9$ \\
Weight $(\mathrm{kg})$ & $52.95 \pm 5.9$ \\
\hline
\end{tabular}
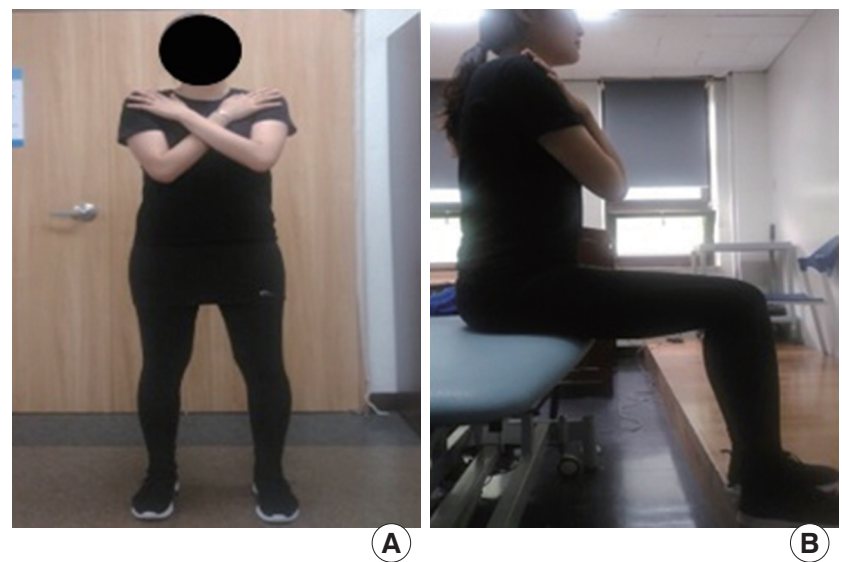

Figure 2. (A) standing position, (B) stitting position. 
의 기울기를 측정하였다(Figure 1).

\section{3. 실험방법}

PALM과 Clino로 골반 기울임 각도를 측정하기 위해 바로 선 자세 시 다리는 어깨너비로 벌리고 팔을 X자로 모아 가슴 위에 위치시켰다 앉은 자세 시 큰 돌기(greater trochanter)와 종아리뼈 머리(fibular head) 를 이은 선이 지면과 수평을 이루게 하고 팔을 X자로 모아 가슴 위에 위치시켰다(Figure 2). 이때 각 실험도구의 오차를 줄이기 위해 레깅 스를 입고 측정하였다. PALM을 사용하여 골반의 기울기를 측정하기 위해 위앞엉덩뼈가시와 위뒤엉덩뼈가시를 촉진한 후 서 있을 때와 앉아있을 때의 골반기울임 각도를 측정하였다. 위앞엉덩뼈가시와 위 뒤엉덩뼈가시를 촉진 시에는 양손가락을 밑에서부터 퍼올리듯이 (scoop) 하여 측정 지점을 정하였다. Clino 또한 PALM의 측정법과 같 이 서 있을 때와 앉아 있을 때의 위앞엉덩뼈가시와 위뒤엉덩뼈가시 를 촉진하고 그사이 연결선을 테이프로 표시한 후 경사도를 측정하 였다(Figure 3). 본 실험에는 검사자 두 명과 기록자 한 명으로 이루어 졌다. 검사자 1 이 각각 두 번씩 측정하고 검사자2가 각각 한 번씩 측정 하여 검사자 내 신뢰도와 검사자 간 신뢰도를 알아보았다. 검사자 내 신뢰도를 위하여, 검사자 1 의 측정이 끝나면 부착했던 테이프를 제거 하고 10 분 뒤 검사자 1 이 다시 측정을 하였다. 검사자 간 신뢰도를 위 하여, 검사자 1 이 마지막 측정을 마치면 부착했던 테이프를 제거하고

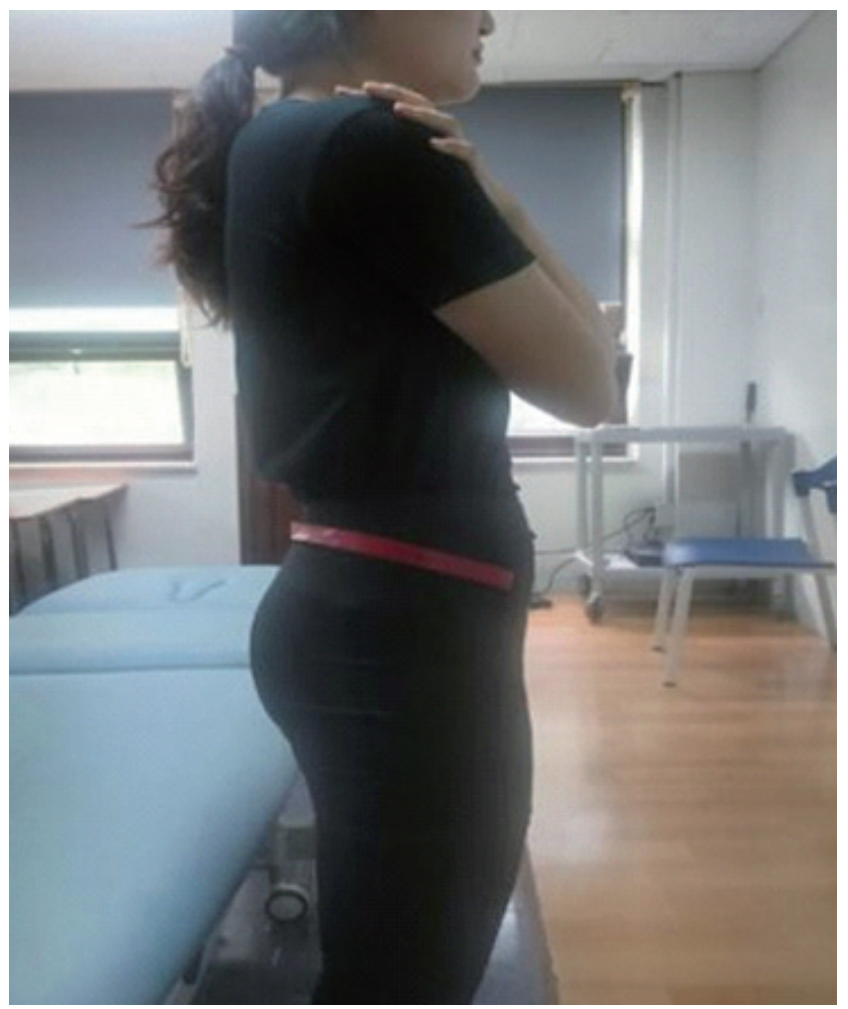

10 분 뒤 검사자 2 가 다시 부착하여 실험을 진행하였다. 한 명의 실험대 상자를 측정할 때, PALM과 Clino의 측정순서는 무작위 순서로 진행 하였다. 모든 측정값은 기록자만이 PALM과 Clino에서 나타내고 있 는 수치를 보고 기록하는 블라인드 실험을 진행하였다. 휴식시간은 측정 후 10 분이 주어졌다.

\section{4. 자료분석}

본 실험의 실험결과는 SPSS (IBM statistic ver. 20)를 이용하여 통계처리 하고, 평균 \pm 표준편차로 기술하였다. One-sample Kolmogorov-Smirnov test를 통해 측정의 정규분포를 확인하였다. 본 연구에서는 신뢰도 평가 방법으로 급내상관계수(ICC 3,1$)$ 를 사용하였다. 급내상관계수 값의 범 위는 0 에서 +1 사이에 있다. 1 이면 완전 일치를 뜻하며 ICC 값이 0.81-1.0 사이일 경우 “very good”, 0.61-0.80 사이일 경우 "good”, 0.41-0.60 사이일 경우 “moderate", 0.21-0.40 사이일 경우 “fair", 그리고 0.20 이하이면 "poor" 신뢰도를 의미한다. ${ }^{17}$ 타당도 평가방법은 피어슨 상관계수를 사 용하였다. 통계학적 유의수준은 0.05 로 정하였다. 모든 통계학적 분석은 SPSS Statistics software 23 (IBM Corp., Armonk, NY, USA)을 사용하였다.

\section{결 과}

\section{1. 검사자 내/검사자 간 신뢰도 - 서 있는 자세에서 PALM}

서 있는 자세에서 PALM를 이용해 오른쪽 골반기울임을 측정하였을 때 검사자 내 신뢰도는 $\operatorname{ICC}(3.1)=0.89$, 검사자 간 신뢰도는 $\operatorname{ICC}(3.1)=0.85$ 이 었다.

\section{2. 검사자 내/검사자 간 신뢰도 - 서 있는 자세에서 Clino}

서 있는 자세에서 Clino를 이용해 오른쪽 골반기울임을 측정하였을 때 검사자 내 신뢰도는 $\operatorname{ICC}(3.1)=0.87$, 검사자 간 신뢰도는 $\operatorname{ICC}(3.1)=0.82$ 이었다.

\section{3. 검사자 내/검사자 간 신뢰도 - 앉은 자세에서 PALM}

앉은 자세에서 PALM를 이용해 오른쪽 골반기울임을 측정하였을 때 검사자 내 신뢰도는 $\operatorname{ICC}(3.1)=0.92$, 검사자 간 신뢰도는 $\operatorname{ICC}(3.1)=0.87$ 이었다.

\section{4. 검사자 내/검사자 간 신뢰도 - 앉은 자세에서 Clino}

앉은 자세에서 Clino를 이용해 오른쪽 골반기울임을 측정하였을 때 검사자 내 신뢰도는 ICC (3.1) 0.91, 검사자 간 신뢰도는 ICC (3.1)=0.88 이었다.

Figure 3. marking the pelvis with the tape. 
Table 2. Reliability and validity of measurement in standing and sitting position

\begin{tabular}{|c|c|c|c|}
\hline & & $\begin{array}{c}\text { ICC in standing } \\
\text { (95\% confidence interval) } \\
\text { Average }\end{array}$ & $\begin{array}{c}\text { ICC in sitting } \\
\text { (95\% confidence interval) } \\
\text { Average }\end{array}$ \\
\hline \multirow[t]{8}{*}{ Reliability } & PALM intra & $0.89(0.74-0.93)$ & $0.92(0.76-0.95)$ \\
\hline & & $9.00 \pm 3.59 ; 8.95 \pm 3.49$ & $-3.15 \pm 4.65 ;-3.05 \pm 4.80$ \\
\hline & PALM inter & $0.85(0.73-0.91)$ & $0.87(0.74-0.90)$ \\
\hline & & $9.00 \pm 3.36$ & $-3.00 \pm 4.73$ \\
\hline & Clino intra & $0.87(0.72-0.92)$ & $0.91(0.75-0.95)$ \\
\hline & & $9.45 \pm 3.26 ; 9.60 \pm 3.49$ & $-3.45 \pm 4.59 ;-3.35 \pm 4.75$ \\
\hline & Clino inter & $0.82(0.69-0.90)$ & $0.88(0.73-0.93)$ \\
\hline & & $9.55 \pm 3.39$ & $-3.4 \pm 4.83$ \\
\hline Validity & PALM vs. Clino & $0.83(p<0.05)$ & $0.89(p<0.05)$ \\
\hline
\end{tabular}

\section{5. 타당도}

서 있는 자세에서 PALM과 Clino의 타당도는 ICC $(3.1)=0.83$ 이었고 앉 은 자세에서 타당도는 $r=0.89$ 이었다 $(\mathrm{p}<0.05)(T a b l e 2)$.

\section{고 찰}

골반의 앞기울임, 뒷기울임의 정렬은 자세 안정성, 균형, 보행에 영향 을 미치며, 허리뼈 정렬에 직접적으로 영향을 줄 수 있다. 또한 일반적 으로 엉치허리와 다리 기능장애, 허리통증이 있는 환자를 평가할 때 골반 위치의 평가가 수행된다.

이 연구의 실험 결과는 다음과 같이 나왔다. 앉은 자세에서 PALM 의 검사자 내/검사자 간 신뢰도는 ICC값 $0.92 / 0.87$ 이었고, 서있는 자세 에서 PALM 검사자 내/검사자 간 신뢰도는 ICC값 $0.89 / 0.85$ 로 서 있을 때 보다 앉은 자세에서 측정한 것이 근소한 차이로 더 높은 신뢰도가 나왔다. Clino에서의 앉은 자세 시 검사자 내/검사자 간 신뢰도는 ICC 값 $0.91 / 0.88$ 이고, 서있는 자세 시 Clino 검사자 내/검사자 간 신뢰도는 ICC값 $0.87 / 0.82$ 로 Clino 또한 앉은 자세에서 측정한 것이 더 높은 신 뢰도가 나왔다. 타당도 역시도 앉은 자세 값 0.89 로 서있는 자세 값 0.83 보다 더 높은 타당도가 나왔다.

과도한 골반기울임 각도는 척추 앞굽음이 비정상적으로 증가된 상태를 의미하며, 각도가 경미할 경우 척추 앞굽음이 감소된 상태를 말한다. 따라서 이 같은 구조를 파악하기 위해 골반기울임각도의 정 확한 평가는 치료에 앞서 임상적으로 상당히 중요하다고 할 수 있다. 골반 기울임을 측정하는데 있어 PALM은 가장 타당하고 신뢰할 수 있는 도구이다. ${ }^{12}$ 하지만 PALM은 비용적으로 비교적 고가이고, 일반 적으로 사용하기에는 어려움이 있다. 그래서 골반기울임을 측정할 때 PALM을 대신해 어플리케이션을 사용할 수 있는지 증명하고자 하 였다.

이와 같은 데이터가 나온 이유는 다음과 같다. 첫 번째로는 앉은 자
세가 서 있는 자세 보다 좋게 나온 이유는 앉은 자세 시에는 골반 중 심이 한쪽으로 치우쳐 고정이 되어 있다. 앉은 자세에서는 골반의 뒤 쪽 기울임 각도가 엉덩허리근육과 넙다리곧은근 그리고 넙다리뒤근 의 근길이에 영향을 받는다고 볼 수 있다. 따라서 앉은 자세에서는 엉 덩관절과 골반을 구성하는 근육들의 길이가 항상 같은 상태에서 신 체 정렬을 유지하고 있고, 이것이 서 있는 자세에 비해자세의 변화율 을 최소화 시킨 것이라고 볼 수 있다.18 서 있는 자세에서는 참가자 근 길이의 장력이 평형구역(neutral zone)에 있기 때문에 허리골반부위가 정상정렬이라도 매 측정시 평형구역 이내의 범위에서는 동일한 정렬 을 유지하기가 더 어렵다고 볼수 있다. ${ }^{19}$

두 번째로 Clino가 PALM과의 비교에서 타당도가 좋게 나온 이유 이다. Clino 역시 골반의 랜드 마크인 위앞엉덩뼈가시와 위뒤엉덩뼈 가시를 잇는 테이프 선을 기준으로 해서 측정하는 방식이고, 골반의 랜드 마크는 충분히 촉진을 반복한다면 동일한 지점을 촉진하여 측 정이 가능하다. 이것이 PALM을 이용하는 방식과 동일하다는 점으 로 볼 때 Clino의 타당도가 좋게 나온 것이다. 또한 본 연구에서는 위 앞엉덩뼈가시와 위뒤엉덩뼈가시를 최대한 일정한 위치에서 찾기 위 해 촉진하는 양손가락을 밑에서부터 퍼올리듯이(scoop) 하여 측정 지점을 정하였다. 따라서 같은 랜드 마크를 찾아서 측정하는 것이 중 점이기 때문에 두 방법 모두 신뢰도 및 타당도가 좋았다. ${ }^{20}$ gold standard로 알려진 PALM과 본 연구에서 증명하고자 하는 새로운 도구인 Clino를 사용하여 앉은 자세 또는 서있는 자세에서 골반 기울임 각도 측정, 비교하였으며 높은 수준의 검사자 내, 그리고 검사자 간 신뢰도 를 보였다.11,21 또한, 이 두 가지 도구를 이용해 측정한 값 사이의 유의 한 차이가 없으므로 PALM을 대체하여 스마트폰에 기초한 어플리케 이션 Clino를 골반 기울임 각도 측정에 이용 할 수 있다. 따라서 Clino 가 임상에서 신뢰도와 타당도 높은 도구로 선자세와 앉은자세에서 골반 기울임 각도를 측정하기 위해 사용될 수 있을 것이다.22

PALM을 이용한 선행연구를 살펴보면, 선 자세에서 골반의 비대칭 
성을 검사했을 때 0.84 (이마면)과 0.98 (시상면)의 검사자 내 신뢰도 그리고 0.65 (이마면)과 0.89 (시상면)의 검사자 간 신뢰도를 확인할 수 있었다. ${ }^{14}$ 선행 연구에서는 시상면에서 골반의 비대칭성을 검사하게 위해 양쪽의 위앞엉덩뼈가시와 위뒤엉덩뼈가시를 촉진하여 평가하 였고, 이마면에는 엉덩뼈 능선의 가장 윗부분을 촉진하여 골반 비대 칭성을 평가하였다. 선행연구에서의 결과를 보면, 시상면에서의 골반 기울임 각도는 8.35-11.3도 사이를 정상으로 판단하는데, 검사자 내/ 검사자 간 신뢰도는 $0.98 / 0.89$ 를 나타냈다. 본 연구에서도 PALM을 이 용한 결과값을 보면 시상면에서의 골반 기울임 각도가 평균 8.95-9.60 도 사이를 기록했고, 신뢰도 역시 임상적으로 신뢰할 수 있는 수준으 로 보여졌다. Clino를 이용한 측정에서도 높은 신뢰도 및 타당도를 보 였기 때문에 임상적으로 PALM을 대체하여 Clino를 사용하는 것이 추천될 수 있다고 생각한다.

이 연구에서는 제한점이 있다. 첫째, 젊고, 건강한 여성 대상자만 선 정하여 연구를 진행하였다. 고령의 환자나 디스크환자 또는 뇌성마 비, 척추옆굽음증 등 척추 정렬이 바르지 못한 자들이나 다른 성별의 대상자에게는 이 연구방법이 다른 결과가 나올 수 있다. 추후 연구에 서는 다양한 연구대상자 그룹과 자세에 있어서도 서있는 자세와 앉 은 자세뿐만 아니라 앞으로 구부린 자세, 한쪽으로 치우친 자세 등 여 러 자세로 변형한 상태에서 골반 기울임 각도 측정법 신뢰도와 타당 도 연구가 필요하다.

Clino를 사용하여 골반의 기울기를 측정할 때 테이프를 이용하여 경사를 만들고 어플리케이션을 이용하여 각도를 재야하지만 테이프 를 붙일 때 골반의 능선으로 인해 선이 일직선이 되지 않고 위 아래로 휘는 경우가 발생할 수 있다. 따라서 청바지 같은 두꺼운 소재의 옷 보 다는 몸에 달라붙는 레깅스와 같은 의류 입고 Clino를 사용하여야 신뢰할 수 있는 측정 값이 나올 것이다.

\section{ACKNOWLEDGEMENTS}

본 연구는 한국연구재단 기초과학연구 (생애첫연구)의 연구비 지원 을 받았음 (No. 2017R1C1B5076172).

\section{REFERENCES}

1. Gu JS, Choi SJ, Choi HS et al. Effects of pelvic tilt training using inclinometer on joint position sense and postural alignment in patients with chronic stroke. J Kor Phys Ther. 2016;28(1):33-8.

2. DeSilva JM, Rosenberg KR. Anatomy, development, and function of the human pelvis. Anat Rec. 2017;300(4):628-32.

3. Endo K, Suzuki H, Nishimura H et al. Sagittal lumbar and pelvic alignment in the standing and sitting positions. J Orthop Sci. 2012;17(6):6826.
4. Chaléat-Valayer E, Mac-Thiong JM, Paquet J et al. Sagittal spino-pelvic alignment in chronic low back pain. Eur Spine J. 2011;20(5):634-40.

5. Schache AG, Blanch PD, Murphy AT. Relation of anterior pelvic tilt during running to clinical and kinematic measures of hip extension. Br J Sports Med. 2000;34(4):279-83.

6. Park SH, Yuk GC, Ahn SH et al. Lumbar Spine Kinematics during anterior and posterior pelvic tilting in supine and prone positions. J Kor Phys Ther. 2011;23(6):9-14.

7. Schache AG, Blanch P, Rath D et al. Three-dimensional angular kinematics of the lumbar spine and pelvis during running. Hum Mov Sci. 2002;21(2):273-93.

8. Sullivan MK, Dejulia JJ, Worrell TT. Effect of pelvic position and stretching method on hamstring muscle flexibility. Med Sci Sports Exerc. 1992;24(12):1383-9.

9. Beardsley C, Egerton T, Skinner B. Test-re-test reliability and inter-rater reliability of a digital pelvic inclinometer in young, healthy males and females. Peer J. 2016;4:1881.

10. Gajdosik R, Simpson R, Smith R et al. Pelvic tilt:Intratester reliability of measuring the standing position and range of motion. Phys Ther. 1985;65(2):169-74.

11. Herrington L. Assessment of the degree of pelvic tilt within a normal asymptomatic population. Man Ther. 2011;16(6):646-8.

12. Kim JH, Chang SK. The Effects of Robo-horseback riding with changes of pelvic tilting and speeds on muscle activities of trunk and lower limb. J Kor Phys Ther. 2014;26(5):290-5.

13. Petrone MR, Guinn J, Reddin A et al. The accuracy of the palpation meter (PALM) for measuring pelvic crest height difference and leg length discrepancy. J Orthop Sports Phys Ther. 2003;33(6):319-25.

14. Hagins M, Brown M, Cook C et al. Intratester and intertester reliability of the palpation meter (PALM) in measuring pelvic position. J Manual Manip Ther. 1998;6(3):130-6.

15. Hayes AM, Place HM, Hayden A et al. The use of the PALM palpation meter for measuring pelvic tilt and its correlation with radiographic measures. The Spine Journal. 2016;16(10):S355-6.

16. Sahrmann SA. Diagnosis and treatment of movement impairment syndromes. St Louis, Mosby. 2002.

17. Yoon TL. Validity and reliability of an inertial measurement unit-based 3D angular measurement of shoulder joint motion. J Kor Phys Ther. 2017;29(3):145-51

18. Kinsella SM, Harvey NL. A comparison of the pelvic angle applied using lateral table tilt or a pelvic wedge at elective caesarean section. Anaesthesia. 2012;67(12):1327-31.

19. Panjabi MM. The stabilizing system of the spine. Part II. Neutral zone and instability hypothesis. J Spinal Disord. 1992;5(4):390-6.

20. Haeri Seyed MJ, Razeghi M, TaghizadehIS et al. Designing a new method for measuring lumbar lordosis. Qom university of medical sciences journal. 2015;9(9):35-41.

21. Bonifácio D, Lopes Í, Martins F et al. Intra-and inter-rater reliability in photogrammetric pelvic tilt angles analysis. IJTR. 2013;20(2):86-90.

22. Kim SJ, Jeong SY, Yoon TL. The effect of visual feedback of head angles with using a mobile posture-aware system on craniocervical angle and neck and shoulder muscles fatigue during watching the smartphone. J Kor Phys Ther. 2018;30(2):47-53. 